\title{
Guideline Familiarity Predicts Variation in Self-Reported Use of Routine Surveillance PET/CT by Physicians Who Treat Head and Neck Cancer
}

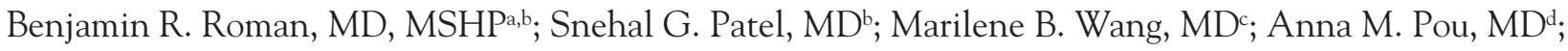 \\ F. Christopher Holsinger, MDe; David Myssiorek, MD; David Goldenberg, MD; \\ Samuel Swisher-McClure, MD, MSHPh; Alexander Lin, $\mathrm{MD}^{\mathrm{h}}$; Jatin P. Shah, MD ${ }^{\mathrm{b}}$; and Judy A. Shea, $\mathrm{PhD}^{\mathrm{a}}$
}

\begin{abstract}
Background: Use of routine surveillance testing beyond guideline recommended levels is common in many oncologic disciplines, including head and neck cancer. The impact of guideline familiarity and other physician characteristics on surveillance imaging use are not well understood. Methods: A cross-sectional national survey was performed of physicians responsible for surveillance of patients with head and neck squamous cell carcinoma (HNSCC). The primary outcome was self-reported use of routine surveillance PET/CT in asymptomatic patients. A secondary outcome was familiarity with guideline recommendations. Using multivariable regression, the impact of guideline familiarity and other physician characteristics on PET/CT use was examined. Results: Of the 502 responders, 79\% endorsed ever using PET/ CT scans for routine surveillance imaging, and $39 \%$ were high imaging users (used PET/CT scans on more than half of their asymptomatic patients); $76 \%$ were familiar with the NCCN Clinical Practice Guidelines in Oncology for Head and Neck Cancers recommending against routine surveillance PET/CT scans. Although guideline familiarity was associated with being a low imaging user or a never-user, among those who were familiar with guidelines, $31 \%$ were nonetheless high imaging users and $73 \%$ endorsed ever using PET/CT scans. In multivariable analysis controlling for physician characteristics, guideline familiarity was the strongest predictor of PET/CT use. Conclusions: Familiarity with the NCCN Guidelines predicts self-reported routine surveillance PET/CT use among physicians who treat patients with HNSCC. However, given the observed variation and high levels of imaging even among physicians who are familiar with the guidelines, further research should examine the reasons physicians choose to use surveillance PET/CT scans. (J Natl Compr Canc Netw 2015;13:69-77)
\end{abstract}

\section{Background}

Routine surveillance imaging for asymptomatic patients who have completed initial treatment and had 1 negative baseline scan is not recommended in the NCCN Clinical Practice Guidelines in Oncology (NCCN Guidelines) for Head and Neck Cancers, which recommend only "further reimaging as indicated based

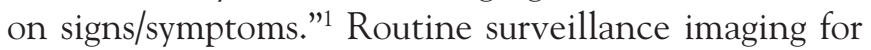

\footnotetext{
From the aRWJ Clinical Scholars Program/Leonard Davis Institute of Health Economics/Department of Medicine, University of Pennsylvania, Philadelphia, Pennsylvania; ${ }^{b} \mathrm{Head}$ and Neck Service, Memorial Sloan Kettering Cancer Center, New York, New York; 'Department of Head and Neck Surgery, University of California, Los Angeles, Los Angeles, California; dDeparment of Otolaryngology-Head and Neck Surgery, Louisiana State University Health Sciences Center, New Orleans, Louisiana; eDepartment of Otolaryngology, Stanford University, Stanford, California; 'Department of Otolaryngology, New York University School of Medicine, New York, New York; 'Division of Otolaryngology-Head and Neck Surgery, Department of Surgery, The Pennsylvania State University-Milton S. Hershey Medical Center, Hershey, Pennsylvania; and hepartment of Radiation Oncology, University of Pennsylvania, Philadelphia, Pennsylvania.
}

asymptomatic patients in other cancer types has been identified as a target for reduction. ${ }^{2-5}$ Recently, PET/ CT for surveillance has been specifically identified by ASCO in the ABIM (American Board of Internal Medicine) Choosing Wisely Campaign as a test that should be avoided by most patients with cancer because of a lack of data about prolonged life or increased well-being, and because false-positives may lead to unnecessary

Submitted August 18, 2014; accepted for publication October 8, 2014. The authors have disclosed that they have no financial interests, arrangements, affiliations, or commercial interests with the manufacturers of any products discussed in this article or their competitors. This research was sponsored by the American Head and Neck Society (AHNS) Education Committee and funded by the University of Pennsylvania Robert Wood Johnson Foundation Clinical Scholars Program.

Correspondence: Benjamin R. Roman, MD, MSHP, Memorial Sloan Kettering Cancer Center, Head and Neck Service, 1275 York Avenue, Room C-1061, New York, NY 10065. E-mail: romanb@mskcc.org 
procedures, treatment, and radiation exposure. ${ }^{6}$ Despite these recommendations, use of surveillance imaging is common in oncology, ${ }^{7-11}$ including in head and neck cancers. ${ }^{12}$ However, physician-level factors related to the decision to use surveillance imaging are not well understood.

Several studies have found that physician demographic and practice characteristics correlate with surveillance testing use in breast and colon cancers. ${ }^{7,10,11}$ Studies outside of oncology have also suggested that guideline familiarity may influence use of medical services. ${ }^{13,14}$ Regarding cancer surveillance testing, physicians' confidence in their knowledge about the appropriateness of surveillance testing was found to correlate with levels of reported use. ${ }^{11}$ However, no identified studies have queried physicians about guideline familiarity specifically and correlated this knowledge with surveillance imaging use.

The goal of this study, a national survey of surgeons and radiation oncologists who treat head and neck squamous cell carcinoma (HNSCC), was to understand the influence of guideline familiarity and other physician characteristics on variation in use of routine PET/CT surveillance imaging. Notably, the goal was not to accurately describe levels of imaging use among surgeons, radiation oncologists, or physician subgroups, because this was presumed to be high, but rather to examine the reasons for variation in reported practice. The hypothesis was that guideline familiarity has a significant effect on surveillance imaging use.

\section{Materials and Methods}

As part of a larger study, a survey was administered in 2013 to a cross-sectional national sample of physicians who treat HNSCC. Because surgeons and radiation oncologists share the burden of surveillance care for patients with HNSCC, the study population was derived from the membership lists of 2 medical societies. American Head and Neck Society (AHNS) members, who are mostly surgeons, were queried if they resided in the United States or Canada. Members of the American Society for Radiation Oncology (ASTRO) were queried if they resided in the United States and Canada and if they had noted an interest in head and neck cancer on their membership profile.

The survey instrument included physician demographic and practice characteristics items, report- ed use of surveillance PET/CT scans after a clinical scenario, and familiarity with guideline recommendations for surveillance imaging. Survey items were developed from a literature review, clinician interviews, and input from experts in survey methodology. Iterative pilot testing was performed to refine items developed for this instrument and to determine optimal ordering.

Study data were collected and managed using REDCap (research electronic data capture) tools hosted by the University of Pennsylvania School of Medicine. ${ }^{15}$ AHNS members received an e-mail invitation directing them to an electronic version of the survey. ASTRO members were mailed paper invitations because of society rules against electronic contact. Nonresponders received a second invitation approximately 1 month after the first. Participants were incentivized with a conditional lottery for an iPad mini.

The primary outcome variable was derived from self-reported use of surveillance PET/CT scans following a single clinical scenario. Physicians were asked to consider their patients with the following criteria: advanced stage (stage III or IV) HNSCC of any subsite, treated with any modality, previously had a negative 12-week baseline posttreatment PET/CT scan, were within 2 years of treatment, and were asymptomatic without concern for recurrence. A range of time up to 2 years was specified because physicians may choose to perform additional imaging at various time points but may be less likely to perform imaging when patients are farther from treatment. It should be noted that the scenario specifically distinguished between the first posttreatment scan, usually performed at 12 weeks, and subsequent surveillance imaging. Physicians were then asked, "In what percentage of your patients do you order PET/CT scans?" Choices were discrete ranges: $0 \% ; 1 \%$ to $25 \% ; 26 \%$ to $50 \% ; 51 \%$ to $70 \% ; 71 \%$ to $90 \%$; and $91 \%$ to $100 \%$.

Physicians who use PET/CT scans more than $50 \%$ of the time were classified as "high imaging users," and those who use PET/CT scans $50 \%$ or less of the time were classified as "low imaging users." A cutoff of 50\% was used to allow comparison between relatively even-sized groups. As a sensitivity analysis to examine the outcome of PET/CT use, physicians were classified as never-users if they answered $0 \%$, and were considered ever-users otherwise.

A secondary outcome measure using the same clinical scenario was familiarity with NCCN Guide- 
line recommendations. No guidelines specific to head and neck cancer that include recommendations for surveillance imaging have been published by other organizations in the United States. Physicians were asked, "Routine surveillance imaging is recommended in the current NCCN Guidelines using the following modalities [check as many as applicable]:" Answer choices were: PET/CT; MRI; CT; None of the above; Not sure. Because PET/CT use was the modality of the primary outcome, physicians were classified as either unfamiliar with NCCN Guidelines recommendations regarding PET/CT scan if they checked "PET/CT scan," or familiar if they did not.

Chi-square statistic, Fisher exact test, and $t$ test were performed to describe variation in imaging use according to physician characteristics and guideline familiarity, and the secondary outcome of guideline familiarity according to physician characteristics. Multivariable logistic regression was performed to examine which factors, including physician characteristics and guideline familiarity, were most predictive of high imaging use. All available physician characteristics except age, which is collinear with years in practice, were used in the model. $P$ values of .05 or less were considered significant. Analyses were conducted using Stata Statistical Software (Release 12.1; Stata Inc., College Station, TX). This study was approved by the University of Pennsylvania Institutional Review Board.

\section{Results}

Invitations were sent to 2125 physicians, including 767 AHNS and 1358 ASTRO members. A total of 520 physicians responded (192 from AHNS and 328 from ASTRO) for a response rate of $24.5 \%$. A total of 117 total invitations were returned to sender or had e-mail delivery failure, for a cooperation rate of $25.9 \%$. The mean age of all AHNS members to whom the survey was sent, including nonresponders, was 52.9 years, whereas the mean age of all ASTRO members sent the survey was 51.0 years. Responses were excluded if they were nonphysicians, physicians other than radiation oncologists and surgeons, still in training, or reported not seeing any patients with head and neck cancer in their practice (total excluded, $\mathrm{n}=18$ ). Table 1 describes demographic and practice characteristics of the 502 remaining physi- cians. Some of these physicians had incomplete surveys and therefore could not be subsequently analyzed for the outcomes of PET/CT use and guideline knowledge.

Figure 1 describes variation among 484 physicians who responded to the question about PET/CT use. Most responders (79\%) were ever-users (ie, endorsed using PET/CT scans for surveillance at least some of the time), and 39\% of physicians answered that they used PET/CT scans more than $50 \%$ of the time. Several demographic features were associated with the level of imaging use (Table 2). High imaging users had been in practice for more years, were more likely to be in private practice and less likely to be in academic settings, and saw a smaller volume of patients with HNSCC in their practice than low imaging users. On sensitivity analysis, no demographic differences were seen between ever-users and neverusers.

\begin{tabular}{|c|c|c|c|}
\hline & Total & $\begin{array}{l}\text { Radiation } \\
\text { Oncologists }\end{array}$ & Surgeons \\
\hline Responders & 502 & $326(65 \%)$ & $176(35 \%)$ \\
\hline $\begin{array}{l}\text { Completed fellows } \\
\text { Yes } \\
\text { No }\end{array}$ & $\begin{array}{l}\text { ip } \\
248(51 \%) \\
239(49 \%)\end{array}$ & $\begin{array}{l}124(38 \%) \\
199(62 \%)\end{array}$ & $\begin{array}{r}124(76 \%) \\
40(24 \%)\end{array}$ \\
\hline $\begin{array}{l}\text { Gender } \\
\text { Male } \\
\text { Female }\end{array}$ & $\begin{array}{r}401(82 \%) \\
86(18 \%)\end{array}$ & $\begin{array}{r}260(80 \%) \\
64(20 \%)\end{array}$ & $\begin{array}{r}141(87 \%) \\
22(13 \%)\end{array}$ \\
\hline Age, mean (SD), y & $49.8(11)$ & $50.2(12)$ & $49.0(10)$ \\
\hline $\begin{array}{l}\text { Years in practice } \\
\quad 1-5 y \\
6-15 y \\
16-25 y \\
\geq 26 y\end{array}$ & $\begin{array}{l}103(21 \%) \\
133(28 \%) \\
125(26 \%) \\
116(24 \%)\end{array}$ & $\begin{array}{l}62(19 \%) \\
87(27 \%) \\
86(27 \%) \\
87(27 \%)\end{array}$ & $\begin{array}{l}41(26 \%) \\
46(30 \%) \\
39(25 \%) \\
29(19 \%)\end{array}$ \\
\hline $\begin{array}{c}\text { Practice setting } \\
\text { Academic }\end{array}$ & $192(40 \%)$ & $78(24 \%)$ & $114(70 \%)$ \\
\hline $\begin{array}{l}\text { Academic } \\
\text { affiliate }\end{array}$ & $84(17 \%)$ & $58(18 \%)$ & $26(16 \%)$ \\
\hline $\begin{array}{l}\text { Community } \\
\text { hospital }\end{array}$ & $105(22 \%)$ & $95(30 \%)$ & $10(6 \%)$ \\
\hline $\begin{array}{l}\text { Private } \\
\text { practice }\end{array}$ & $103(21 \%)$ & $91(28 \%)$ & $12(7 \%)$ \\
\hline \multicolumn{4}{|c|}{ Volume of head and neck cancer seen in practice } \\
\hline $1 \%-25 \%$ & $246(50 \%)$ & $230(80 \%)$ & $16(10 \%)$ \\
\hline $26 \%-50 \%$ & $69(14 \%)$ & $50(15 \%)$ & $19(12 \%)$ \\
\hline$>50 \%$ & $173(35 \%)$ & $44(14 \%)$ & $129(79 \%)$ \\
\hline
\end{tabular}

Numbers do not always sum to total for column because of occasional missing data. Percentages may not sum to $100 \%$ because of rounding. 
Table 3 describes NCCN Guideline familiarity according to physician demographic and practice characteristics among the 455 physicians who responded to the guideline familiarity question. Of these, $76 \%$ were familiar with NCCN Guidelines. Although only $24 \%$ of responders believed that NCCN Guidelines recommend surveillance PET/ CT scans, $41 \%$ of responders overall believed that surveillance imaging with some modality was recommended (PET/CT, MRI, or CT; data not shown). Physicians who believed that NCCN Guidelines recommended PET/CT surveillance had been in practice for more years than those who were correct $(P=.02)$. There were no differences in guideline familiarity according to physician medical specialty, fellowship training, gender, practice setting, or practice volume characteristics.

Table 4 describes variation in PET/CT imaging use according to familiarity with the guideline among the 454 physicians who responded to both of these questions. Among physicians unfamiliar with NCCN Guidelines, 66\% were high imaging users and $98 \%$ were ever-users. Among physicians familiar with the NCCN Guidelines, 31\% were nonetheless high imaging users and $73 \%$ were nonetheless everusers $(P<.0001$, for both $)$.

Table 5 describes the results of multivariable logistic regression to determine predictors of high imaging use and ever-use. Guideline familiarity was the only significant predictor (high vs low odds ratio [OR], 4.47; CI, 2.72-7.34; $P<.0001$; ever vs never

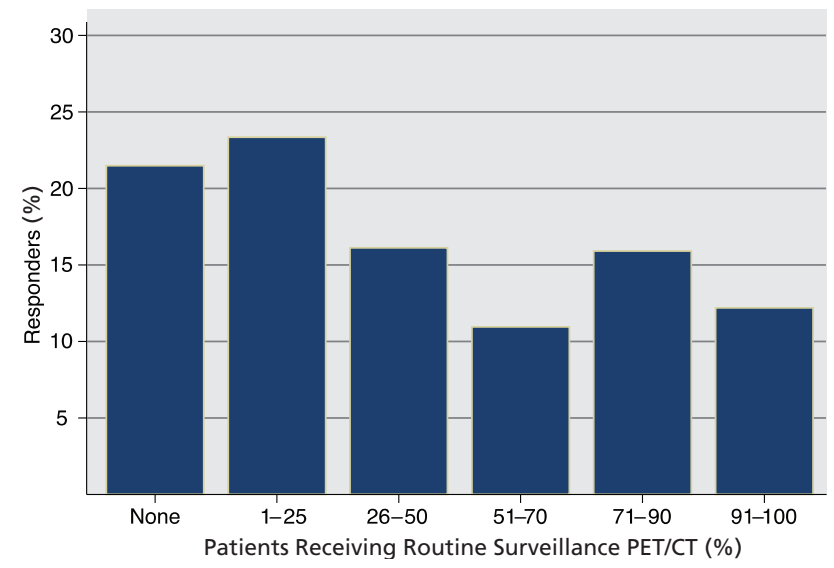

Figure 1 Self-reported use of PET/CT for routine surveillance imaging in asymptomatic patients. After a single clinical scenario, physicians were asked, "What percentage of your patients with head and neck cancer received routine surveillance PET/CT scans?" Those who answered more than "none" were ever-users. Those who answered $\geq 51 \%$ were highimaging users. There were 484 responses to this question.
OR, 39.24; CI, 5.34-288.53; P<.0001). Physician characteristics that correlated with high imaging use on bivariate analysis, including years in practice, practice setting, and case volume, were not predictive on multivariable analysis.

\section{Discussion}

This survey describes variation in the use of routine surveillance PET/CT scans for head and neck cancer survivors according to physician demographics and familiarity with NCCN Guidelines. Most responders endorsed using routine surveillance PET/CT scans for asymptomatic patients after an initial negative 12-week posttreatment scan, and many reported using PET/CT for most of their patients. Although most physicians surveyed were familiar with guidelines recommending against routine surveillance imaging in asymptomatic patients, reported rates of high use even among this group suggest that imaging use was not deterred by this consensus recommendation. Conversely, physicians unfamiliar with NCCN Guidelines were significantly more likely to report frequent PET/CT use in this setting.

The fact that familiarity with NCCN Guidelines correlates with use of PET/CT may be expected but, to the authors' knowledge, the relationship and its strength have not been previously demonstrated in the setting of cancer surveillance. The findings have important implications in all oncologic disciplines in which surveillance imaging is used beyond levels recommended in guidelines, and may be viewed from at least 2 perspectives.

On the one hand, those who write guidelines may view the findings as supportive of their efforts, namely that physicians' practice may be influenced by familiarity with guidelines. ${ }^{16}$ Most guideline recommendations and quality measures currently address what should be done. ${ }^{17}$ Guideline recommendations against certain practices may be of particular interest in the future. This study concerns the latter and may confirm the role of guideline development in addressing overuse. In this context, increased education and dissemination efforts could focus on physicians who are unfamiliar with the NCCN Guidelines. The finding of demographic differences in surveillance practice patterns in this study, not dissimilar to findings in the settings of cancer screening and surveillance, ${ }^{7,11,18}$ suggests areas of emphasis for these efforts. 
Predictors of Surveillance PET/CT Use

\begin{tabular}{|c|c|c|c|c|c|c|c|}
\hline & \multirow[b]{2}{*}{$\begin{array}{l}\text { Total } \\
\text { (Column \%) }\end{array}$} & \multicolumn{3}{|c|}{ Low vs High Users } & \multicolumn{3}{|c|}{ Never- vs Ever-Users } \\
\hline & & $\begin{array}{l}\text { Low Users } \\
\text { (Row \%) }\end{array}$ & $\begin{array}{l}\text { High Users } \\
\text { (Row \%) }\end{array}$ & $P$ Value & $\begin{array}{l}\text { Never-Usersc } \\
\text { (Row \%) }\end{array}$ & $\begin{array}{l}\text { Ever-Users }^{d} \\
(\text { Row \%) }\end{array}$ & $P$ Value \\
\hline Responders & 484 & $295(61 \%)$ & $189(39 \%)$ & & $104(21 \%)$ & $380(79 \%)$ & \\
\hline $\begin{array}{l}\text { Medical specialty } \\
\text { Surgerye } \\
\text { Radiation oncology }\end{array}$ & $\begin{array}{l}160(33 \%) \\
324(67 \%)\end{array}$ & $\begin{array}{l}105(63 \%) \\
190(59 \%)\end{array}$ & $\begin{array}{r}55(34 \%) \\
134(41 \%)\end{array}$ & .139 & $\begin{array}{l}31(19 \%) \\
73(23 \%)\end{array}$ & $\begin{array}{l}129(81 \%) \\
251(77 \%)\end{array}$ & .427 \\
\hline \multicolumn{4}{|c|}{ Completed surgical or radiation oncology fellowship } & .073 & & & .248 \\
\hline $\begin{array}{l}\text { Yes } \\
\text { No }\end{array}$ & $\begin{array}{l}242(50 \%) \\
239(50 \%)\end{array}$ & $\begin{array}{l}157(64 \%) \\
136(57 \%)\end{array}$ & $\begin{array}{r}85(35 \%) \\
103(43 \%)\end{array}$ & & $\begin{array}{l}47(19 \%) \\
56(23 \%)\end{array}$ & $\begin{array}{l}195(81 \%) \\
183(77 \%)\end{array}$ & \\
\hline $\begin{array}{l}\text { Sex } \\
\text { Male } \\
\text { Female }\end{array}$ & $\begin{array}{r}396(83 \%) \\
84(18 \%)\end{array}$ & $\begin{array}{r}243(61 \%) \\
48(57 \%)\end{array}$ & $\begin{array}{r}153(39 \%) \\
36(43 \%)\end{array}$ & .472 & $\begin{array}{l}83(21 \%) \\
19(23 \%)\end{array}$ & $\begin{array}{r}313(79 \%) \\
65(77 \%)\end{array}$ & .736 \\
\hline $\begin{array}{l}\text { Years in practice } \\
1-5 y \\
6-15 y \\
16-25 y \\
\geq 26 y\end{array}$ & $\begin{array}{l}103(22 \%) \\
131(28 \%) \\
123(26 \%) \\
113(24 \%)\end{array}$ & $\begin{array}{l}73(71 \%) \\
76(58 \%) \\
78(63 \%) \\
57(50 \%)\end{array}$ & $\begin{array}{l}30(29 \%) \\
55(42 \%) \\
45(37 \%) \\
56(50 \%)\end{array}$ & .017 & $\begin{array}{l}25(24 \%) \\
24(18 \%) \\
26(21 \%) \\
21(19 \%)\end{array}$ & $\begin{array}{r}78(76 \%) \\
107(82 \%) \\
97(79 \%) \\
92(81 \%)\end{array}$ & .666 \\
\hline $\begin{array}{l}\text { Practice setting } \\
\text { Academic tertiary } \\
\text { Academic affiliate } \\
\text { Community hospital } \\
\text { Private practice }\end{array}$ & $\begin{array}{r}188(39 \%) \\
82(17 \%) \\
105(22 \%) \\
103(22 \%)\end{array}$ & $\begin{array}{r}126(67 \%) \\
58(71 \%) \\
59(56 \%) \\
47(46 \%)\end{array}$ & $\begin{array}{l}62(33 \%) \\
24(29 \%) \\
46(44 \%) \\
56(54 \%)\end{array}$ & .001 & $\begin{array}{l}41(22 \%) \\
23(28 \%) \\
23(22 \%) \\
13(13 \%)\end{array}$ & $\begin{array}{r}147(78 \%) \\
59(72 \%) \\
82(78 \%) \\
90(87 \%)\end{array}$ & .073 \\
\hline $\begin{array}{l}\text { Volume of head and ne } \\
\qquad \begin{array}{l}1 \%-25 \% \\
26 \%-50 \% \\
>50 \% \text { of practice }\end{array}\end{array}$ & $\begin{array}{c}\text { cancer seen i } \\
246(51 \%) \\
69(14 \%) \\
167(35 \%)\end{array}$ & $\begin{array}{l}\text { ractice } \\
\qquad 136(55 \%) \\
42(61 \%) \\
117(70 \%)\end{array}$ & $\begin{array}{r}110(45 \%) \\
27(39 \%) \\
51(30 \%)\end{array}$ & .013 & $\begin{array}{l}54(22 \%) \\
15(22 \%) \\
35(21 \%)\end{array}$ & $\begin{array}{r}192(78 \%) \\
54(78 \%) \\
133(79 \%)\end{array}$ & .963 \\
\hline
\end{tabular}

Numbers do not always sum to total for column because of occasional missing data.

a"Low users" order surveillance PET/CT scans $\leq 50 \%$ of the time for asymptomatic patients.

b"High users" order surveillance PET/CT scans $>50 \%$ of the time for asymptomatic patients.

c"Never-users" never order surveillance PET/CT scans for asymptomatic patients.

d"Ever-users" order surveillance PET/CT scans on at least some of their asymptomatic patients.

eSurgery includes ear, nose, and throat surgeons, general surgeons, and oral and maxillofacial surgeons.

However, the findings may be viewed from the perspective of uncertainty about the true benefit of routine surveillance imaging and concern about the validity of the guideline recommendation. This view is supported by the fact that many physicians familiar with the guidelines are nonetheless high imaging users.

This perspective necessitates a brief review of the literature regarding the benefits of routine surveillance PET/CT scans for head and neck cancer. The authors again distinguish between routine surveillance scans performed well after treatment and the first posttreatment scan, usually performed at 12 weeks, which has been shown to impact decisionmaking, predict prognosis, and be a cost-effective strategy that can decrease planned neck dissections. ${ }^{19-23}$ Subsequent PET or PET/CT scans in most studies have moderate specificity and positive pre- dictive value, very good sensitivity and negative predictive value, and a yield of recurrent disease in asymptomatic patients between 5\% and 36\%, and may lead to changes in management in approximately 1 of 3 cases. ${ }^{21,24-33}$ These statistics may be beneficial to the patient, especially the high negative predictive value. ${ }^{21,33}$ In addition, PET positivity may be an important prognosticator of survival. ${ }^{21}$

However, only 2 identified studies examined clinical outcomes related to the provision of PET/CT scans. These studies found no difference in survival in patients with metastases detected by PET/CT compared with other imaging modalities, ${ }^{34}$ and no difference in survival in patients whose recurrences were detected by PET/CT versus clinical examination. ${ }^{35}$ These studies are limited by their retrospective nature, but because of the overall poor outcomes even for patients with surgically resectable recurrent 
Roman et al

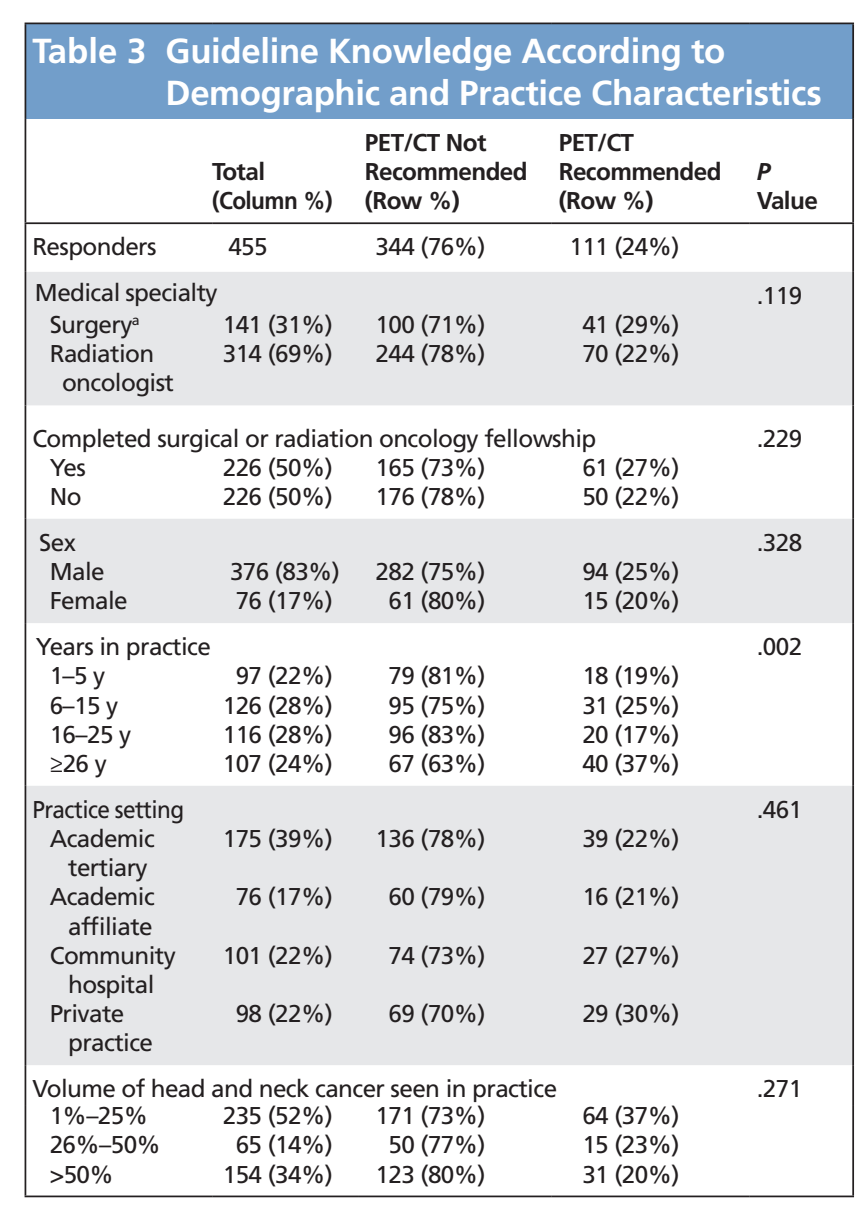

Numbers do not always sum to total for column because of occasional missing data.

asurgery includes ear, nose, and throat surgeons, general surgeons, and oral and maxillofacial surgeons.

HNSCC $^{36-38}$ and the low yield of these recurrences detected in asymptomatic patients, ${ }^{21,26,28,29,31,32}$ whether a survival advantage for occasional earlier detection could be found is unclear. Notably, although not reviewed in depth here, similar doubts exist about the impact of surveillance imaging on survival in many other oncologic disciplines. ${ }^{2,3,5}$ Even in colorectal and breast cancer, in which some evidence suggests a benefit, ${ }^{39-43}$ other data are less certain, ${ }^{4-50}$ leading some authors to argue that a rational scientific approach is to assume that intensifying follow-up does not improve survival. ${ }^{4}$

Nonetheless, the level of variation in use suggests that other reasons exist for ordering surveillance PET/CT scans in asymptomatic patients. For example, physicians may not be aware of the lack of supportive survival data, or may remain optimistic about improved outcomes based on their personal experience. This belief about expected outcomes has been cited as a reason that physicians may not follow guidelines ${ }^{13}$ or may have a difficult time changing health care practices that are already in use..${ }^{51}$ Other attitudes, beliefs, and pressures may play a role in the decision to use surveillance PET/CT scans, such as patient expectations or beliefs about the importance of reassurance provided by negative scans..$^{52,53}$

This study has several important limitations. First, the response rate inhibits the generalizability of the results to the entire population of clinicians who treat HNSCC. However, a response rate of $25.9 \%$ is within the range of responses to other surveys of physicians in this field $(2.8 \%-46.0 \%),{ }^{52-55}$ and slightly higher than for one previous survey of both head and neck surgeons and radiation oncologists $(22.0 \%) .^{56}$ In addition, limited data were available about nonresponders, but the responders seem well matched with the overall population of AHNS and ASTRO members in terms of age. Finally, because of the levels of both imaging and unfamiliarity with the NCCN Guidelines, the authors contend that somewhat different levels would not detract from the significance of their interaction, which was the key finding.

A second and related limitation is that the survey relies on self-reported use of imaging, which is subject to recall error and social desirability bias. Recall error might be magnified if responders conflated scans performed for asymptomatic patients without any concern for recurrence with scans performed for patients in whom there was some concern for recurrence, even if they were asymptomatic. Nonetheless, even if such recall errors were occasionally made, the authors again contend that this would not detract from the noted interaction between guideline familiarity and use. Self-reported response to clinical vignettes has been shown to correlate to actual use in other scenarios, ${ }^{57,58}$ and although used in cancer surveillance, ${ }^{11}$ it has not yet been validated. However, regardless of errors in the reported amount of imaging in this study, the true level would still likely be high compared with the amount recommended by guidelines.

A third limitation is that this survey pooled an uneven sample of surgeons and radiation oncologists. However, pooling the 2 specialty groups is justified to support the aim of the study-describe the interaction between guideline familiarity, physician demographics, and imaging use among all physicians responsible for the follow-up of patients with 
Predictors of Surveillance PET/CT Use

\begin{tabular}{|c|c|c|c|c|c|c|c|}
\hline & Total & $\begin{array}{l}\text { Low Usersa } \\
\text { (Row \%) }\end{array}$ & $\begin{array}{l}\text { High Users } \\
\text { (Row \%) }\end{array}$ & $P$ Value & $\begin{array}{l}\text { Never-Usersc } \\
\text { (Row \%) }\end{array}$ & $\begin{array}{l}\text { Ever-Users } \\
\text { (Row \%) }\end{array}$ & $P$ Value \\
\hline $\begin{array}{l}\text { Believe NCCN } \\
\text { recommends PET/CT } \\
\text { surveillance imaging }\end{array}$ & 454 & $276(61 \%)$ & $178(39 \%)$ & & $96(21 \%)$ & $358(79 \%)$ & \\
\hline Yes (incorrect) & $111(24 \%)$ & $38(34 \%)$ & $73(66 \%)$ & \multirow{2}{*}{$<.0001$} & $2(2 \%)$ & $109(98 \%)$ & \multirow{2}{*}{$<.0001$} \\
\hline No (correct) & $343(76 \%)$ & $238(69 \%)$ & $105(31 \%)$ & & $94(27 \%)$ & $249(73 \%)$ & \\
\hline
\end{tabular}

Numbers do not always sum to total for column because of occasional missing data.

a"Low users" order PET/CT scans $\leq 50 \%$ of the time for asymptomatic patients.

b"High users" order surveillance PET/CT scans $>50 \%$ of the time for asymptomatic patients.

" Never-users" never order surveillance PET/CT scans for asymptomatic patients.

d"Ever-users" order surveillance PET/CT scans on at least some of their asymptomatic patients.

HNSCC-especially because no physician demographic characteristics except age correlated with guideline familiarity. Moreover, multivariable regression accounted for these demographic differences and still found guideline familiarity to be the strongest predictor of imaging use.

\section{Conclusions}

This study shows that although familiarity with the NCCN Guidelines is associated with lower imag- ing use, variation in use persists despite this familiarity. Further research on clinical outcomes such as survival is certainly warranted to understand the impact of routine surveillance imaging in head and neck cancer. However, randomized controlled trials for diagnostic tests have significant obstacles, ${ }^{59}$ making the question about survival difficult to answer concretely. In the absence of these data, further research should also explore the attitudes and beliefs that drive physician decision-making in this setting.

\section{Table 5 Multivariable Regression of Guideline Knowledge and Physician Characteristics Predicting Imaging Use}

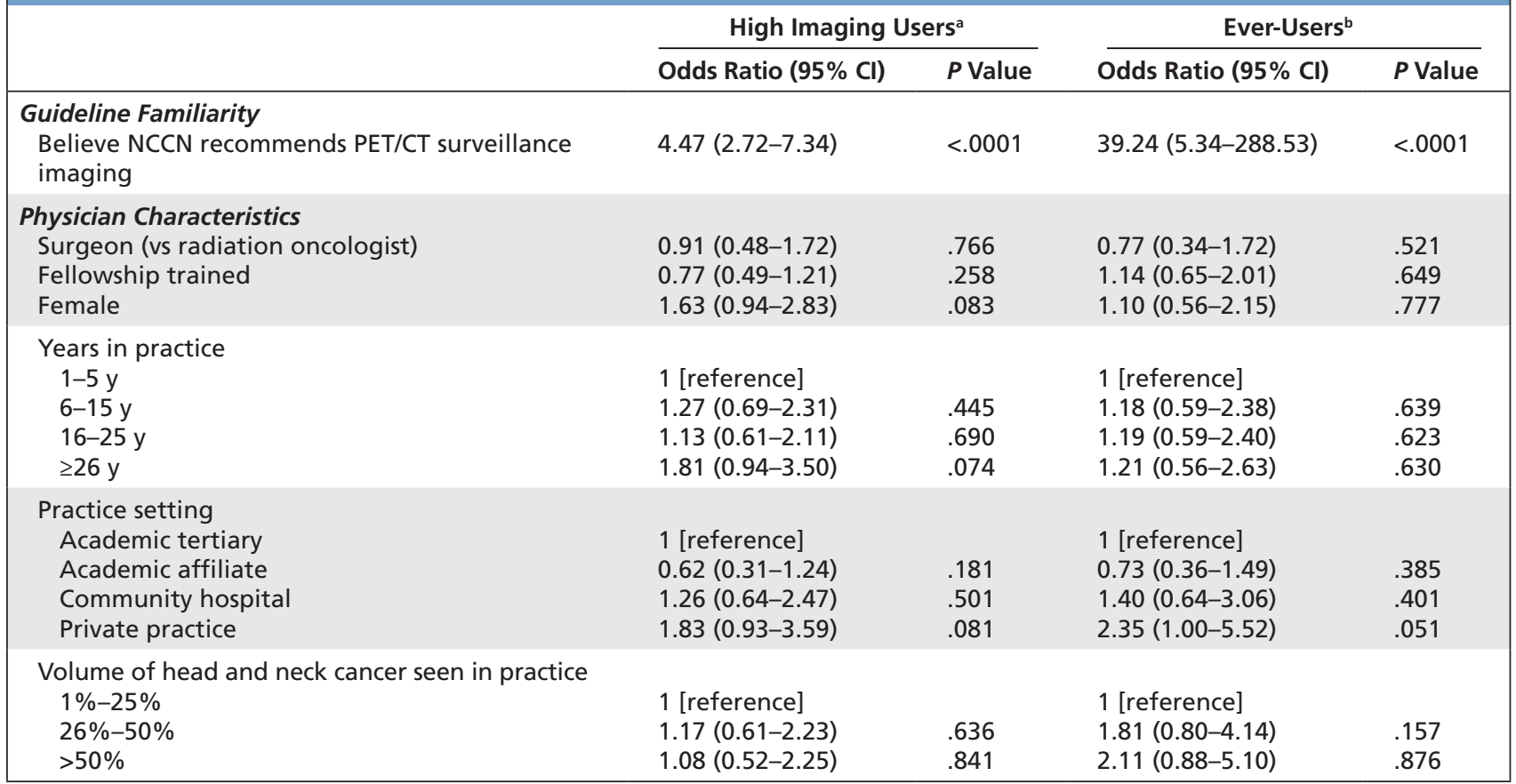

a"High imaging users" are those who order surveillance PET/CT scans $>50 \%$ of the time on their asymptomatic patients

b"Ever-users" order surveillance PET/CT scans on at least some of their asymptomatic patients. 


\section{Acknowledgments}

The authors wish to acknowledge Alan Shi and Jordyn Feingold for their contributions to survey administration and manuscript preparation.

\section{References}

1. Pfister DG, Spencer S, Brizel DM, et al. NCCN Clinical Practice Guidelines in Oncology: Head and Neck Cancers. Version 2.2014. Available at: NCCN.org. Accessed December 12, 2014.

2. Schapira DV, Urban N. A minimalist policy for breast cancer surveillance. JAMA 1991;265:380-382.

3. Smith TJ, Hillner BE. Bending the cost curve in cancer care. N Engl J Med 2011;364:2060-2065.

4. Furman MJ, Lambert LA, Sullivan ME, Whalen GF. Rational follow-up after curative cancer resection. J Clin Oncol 2013;31:1130-1133.

5. Armitage JO. Who benefits from surveillance imaging? J Clin Oncol 2012;30:2579-2580.

6. American Society of Clinical Oncology. 10 Things Physicians and Patients Should Question. Choosing Wisely Web site. Available at: http://www. choosingwisely.org/doctor-patient-lists/american-society-of-clinicaloncology/. Accessed December 12, 2014.

7. Keating NL, Landrum MB, Guadagnoli E, et al. Surveillance testing among survivors of early-stage breast cancer. J Clin Oncol 2007;25:1074-1081.

8. Grunfeld E, Hodgson DC, Del Giudice ME, Moineddin R. Populationbased longitudinal study of follow-up care for breast cancer survivors. J Oncol Pract 2010;6:174-181.

9. Salloum RG, Hornbrook MC, Fishman PA, et al. Adherence to surveillance care guidelines after breast and colorectal cancer treatment with curative intent. Cancer 2012;118:5644-5651.

10. Potosky AL, Han PK, Rowland J, et al. Differences between primary care physicians' and oncologists' knowledge, attitudes and practices regarding the care of cancer survivors. J Gen Intern Med 2011;26:1403-1410.

11. Han PK, Klabunde CN, Noone AM, et al. Physicians' beliefs about breast cancer surveillance testing are consistent with test overuse. Med Care 2013;51:315-323.

12. Myssiorek D, Roman B, Wang M, et al. Trends in utilization of FDG PET imaging in the American Head and Neck Society. Presented at the American Head and Neck Society 2009 Annual Meeting; May 30-31, 2009; Phoenix, Arizona.

13. Cabana MD, Rand CS, Powe NR, et al. Why don't physicians follow clinical practice guidelines? A framework for improvement. JAMA 1999;282:1458-1465.

14. Espeland A, Baerheim A. Factors affecting general practitioners' decisions about plain radiography for back pain: implications for classification of guideline barriers—a qualitative study. BMC Health Serv Res 2003;3:8.

15. Harris PA, Taylor R, Thielke R, et al. Research electronic data capture (REDCap) — a metadata-driven methodology and workflow process for providing translational research informatics support. J Biomed Inform 2009;42:377-381.

16. Jagsi R, Huang G, Griffith $K$, et al. Attitudes toward and use of cancer management guidelines in a national sample of medical oncologists and surgeons. J Natl Compr Canc Netw 2014;12:204-212.

17. Mathias JS, Baker DW. Developing quality measures to address overuse. JAMA 2013;309:1897-1898.

18. Kerfoot $\mathrm{BP}$, Holmberg EF, Lawler EV, et al. Practitioner-level determinants of inappropriate prostate-specific antigen screening. Arch Intern Med 2007;167:1367-1372.

19. Ong SC, Schöder H, Lee NY, et al. Clinical utility of 18F-FDG PET/CT in assessing the neck after concurrent chemoradiotherapy for locoregional advanced head and neck cancer. J Nucl Med 2008;49:532-540.

20. Gourin CG, Boyce BJ, Williams HT, et al. Revisiting the role of positronemission tomography/computed tomography in determining the need for planned neck dissection following chemoradiation for advanced head and neck cancer. Laryngoscope 2009;119:2150-2155.

21. Kao J, Vu HL, Genden EM, et al. The diagnostic and prognostic utility of positron emission tomography/computed tomography-based follow-up after radiotherapy for head and neck cancer. Cancer 2009;115:4586-4594.
22. Sher DJ, Tishler RB, Annino D, Punglia RS. Cost-effectiveness of CT and PET-CT for determining the need for adjuvant neck dissection in locally advanced head and neck cancer. Ann Oncol 2010;21:1072-1077.

23. Pryor DI, Porceddu SV, Scuffham PA, et al. Economic analysis of FDGPET-guided management of the neck after primary chemoradiotherapy for node-positive head and neck squamous cell carcinoma. Head Neck 2013;35:1287-1294.

24. Lowe VJ, Boyd JH, Dunphy FR, et al. Surveillance for recurrent head and neck cancer using positron emission tomography. J Clin Oncol 2000;18:651-658.

25. Lee JC, Kim JS, Lee JH, et al. F-18 FDG-PET as a routine surveillance tool for the detection of recurrent head and neck squamous cell carcinoma. Oral Oncol 2007;43:686-692.

26. Perie $S$, Hugentobler A, Susini B, et al. Impact of FDG-PET to detect recurrence of head and neck squamous cell carcinoma. Otolaryngol Head Neck Surg 2007;137:647-653.

27. Salaun PY, Abgral R, Querellou S, et al. Does 18fluoro-fluorodeoxyglucose positron emission tomography improve recurrence detection in patients treated for head and neck squamous cell carcinoma with negative clinical follow-up? Head Neck 2007;29:1115-1120.

28. Abgral R, Querellou S, Potard G, et al. Does 18F-FDG PET/CT improve the detection of posttreatment recurrence of head and neck squamous cell carcinoma in patients negative for disease on clinical follow-up? J Nucl Med 2009;50:24-29.

29. Krabbe Ca, Pruim J, Dijkstra PU, et al. 18F-FDG PET as a routine posttreatment surveillance tool in oral and oropharyngeal squamous cell carcinoma: a prospective study. J Nucl Med 2009;50:1940-1947.

30. Beswick DM, Gooding WE, Johnson JT, Branstetter BF. Temporal patterns of head and neck squamous cell carcinoma recurrence with positronemission tomography/computed tomography monitoring. Laryngoscope 2012;122:1512-1517.

31. Dunsky KA, Wehrmann DJ, Osman MM, et al. PET-CT and the detection of the asymptomatic recurrence or second primary lesions in the treated head and neck cancer patient. Laryngoscope 2013;123:2161-2164.

32. Kostakoglu L, Fardanesh R, Posner M, et al. Early detection of recurrent disease by FDG-PET/CT leads to management changes in patients with squamous cell cancer of the head and neck. Oncologist 2013;18:11081117.

33. McDermott $M$, Hughes $M$, Rath $T$, et al. Negative predictive value of surveillance PET/CT in head and neck squamous cell cancer. AJNR Am J Neuroradiol 2013;34:1632-1636.

34. Spector ME, Chinn SB, Rosko AJ, et al. Diagnostic modalities for distant metastasis in head and neck squamous cell carcinoma: are we changing life expectancy? Laryngoscope 2012;122:1507-1511.

35. Ho AS, Tsao GJ, Chen FW, et al. Impact of positron emission tomography/ computed tomography surveillance at 12 and 24 months for detecting head and neck cancer recurrence. Cancer 2013;119:1349-1356.

36. Zafereo ME, Hanasono MM, Rosenthal DI, et al. The role of salvage surgery in patients with recurrent squamous cell carcinoma of the oropharynx. Cancer 2009;115:5723-5733.

37. Goodwin WJ Jr. Salvage surgery for patients with recurrent squamous cell carcinoma of the upper aerodigestive tract: when do the ends justify the means? Laryngoscope 2000;110 (3 Pt 2 Suppl 93):1-18.

38. Ho AS, Kraus DH, Ganly I, et al. Decision making in the management of recurrent head and neck cancer. Head Neck 2014;36:144-151.

39. Locker GY, Hamilton S, Harris J, et al. ASCO 2006 update of recommendations for the use of tumor markers in gastrointestinal cancer. J Clin Oncol 2006;24:5313-5327.

40. Figueredo A, Rumble RB, Maroun J, et al. Follow-up of patients with curatively resected colorectal cancer: a practice guideline. BMC Cancer 2003;3:26.

41. Rodriguez-Moranta F, Salo J, Arcusa A, et al. Postoperative surveillance in patients with colorectal cancer who have undergone curative resection: a prospective, multicenter, randomized, controlled trial. J Clin Oncol 2006;24:386-393.

42. Jeffery M, Hickey BE, Hider PN. Follow-up strategies for patients treated for non-metastatic colorectal cancer. Cochrane Database Syst Rev 2007:CD002200

43. Lu WL, Jansen L, Post WJ, et al. Impact on survival of early detection of isolated breast recurrences after the primary treatment for breast cancer: a meta-analysis. Breast Cancer Res Treat 2009;114:403-412.

44. Berman JM, Cheung RJ, Weinberg DS. Surveillance after colorectal cancer resection. Lancet 2000;355:395-399. 
45. Kievit J. Follow-up of patients with colorectal cancer: numbers needed to test and treat. Eur J Cancer 2002;38:986-999.

46. Tjandra JJ, Chan MK. Follow-up after curative resection of colorectal cancer: a meta-analysis. Dis Colon Rectum 2007;50:1783-1799.

47. Impact of follow-up testing on survival and health-related quality of life in breast cancer patients. A multicenter randomized controlled trial. The GIVIO Investigators. JAMA 1994;271:1587-1592.

48. Rosselli Del Turco M, Palli D, Cariddi A, et al. Intensive diagnostic follow-up after treatment of primary breast cancer. A randomized trial. National Research Council Project on Breast Cancer follow-up. JAMA 1994:271:1593-1597.

49. Palli D, Russo A, Saieva C, et al. Intensive vs clinical follow-up after treatment of primary breast cancer: 10-year update of a randomized trial. National Research Council Project on Breast Cancer follow-up. JAMA 1999;281:1586.

50. Rojas MP, Telaro E, Russo A, et al. Follow-up strategies for women treated for early breast cancer. Cochrane Database Syst Rev 2005:CD001768.

51. Roman BR, Asch DA. Faded promises: the challenge of deadopting lowvalue care. Ann Intern Med 2014;161:149-150.

52. Meier JD, Oliver DA, Varvares MA. Surgical margin determination in head and neck oncology: current clinical practice. The results of an International American Head and Neck Society Member Survey. Head Neck 2005;27:952-958.
53. Johnson FE, Johnson MH, Clemente MF, et al. Geographical variation in surveillance strategies after curative-intent surgery for upper aerodigestive tract cancer. Ann Surg Oncol 2006;13:1063-1071.

54. Wu AW, Wang MB, Nguyen CT. Surgical practice patterns in the treatment of papillary thyroid microcarcinoma. Arch Otolaryngol Head Neck Surg 2010;136:1182-1190.

55. Malloy KM, Ellender SM, Goldenberg D, Dolan RW. A survey of current practices, attitudes, and knowledge regarding human papillomavirusrelated cancers and vaccines among head and neck surgeons. JAMA Otolaryngol Head Neck Surg 2013;139:1037-1042.

56. Makki FM, Williams B, Rajaraman M, et al. Current practice patterns in the management of glottic cancer in Canada: results of a national survey. J Otolaryngol Head Neck Surg 2011;40:205-210.

57. Peabody JW, Luck J, Glassman P, et al. Comparison of vignettes, standardized patients, and chart abstraction: a prospective validation study of 3 methods for measuring quality. JAMA 2000;283:1715-1722.

58. Peabody JW, Luck J, Glassman P, et al. Measuring the quality of physician practice by using clinical vignettes: a prospective validation study. Ann Intern Med 2004;141:771-780.

59. Tunis S, Whicher D. The National Oncologic PET Registry: lessons learned for coverage with evidence development. J Am Coll Radiol 2009;6:360-365. 